\title{
Causality Relationship between Energy Consumption and Economic Growth in Brazil
}

\author{
Hsiao-Tien Pao ${ }^{*}$, Yi-Ying Li ${ }^{1}$, Hsin-Chia Fu ${ }^{2}$ \\ ${ }^{1}$ Department of Management Science, National Chiao Tung University, Hsinchu City, Chinese Taipei \\ ${ }^{2}$ College of Engineering, Hua Qiao University, Quanzhou, China \\ Email: ${ }^{*}$ htpao@mail.nctu.edu.tw
}

Received 29 May 2014; revised 2 July 2014; accepted 12 July 2014

Copyright (C) 2014 by authors and Scientific Research Publishing Inc.

This work is licensed under the Creative Commons Attribution International License (CC BY). http://creativecommons.org/licenses/by/4.0/

cC) (7) Open Access

\begin{abstract}
This study has investigated the relationship between energy consumption and economic growth in Brazil during the period of 1980-2008. The co-integration test indicates a long-run equilibrium relationship between variables, and energy consumption appears to be real GDP elastic. This elasticity suggests that energy consumption has a great positive influence on changes in income. The causality results from the error correction model reveal a unidirectional short-run causality from energy consumption to economic growth and a bidirectional strong causality between them. These findings suggest that Brazil should adopt a dual strategy of increasing investment in energy infrastructure, and stepping up energy conservation policies to reduce any unnecessary waste of energy, in order to avoid having a negative effect on economic growth by reducing energy consumption. In contrast, energy conservation is expected to increase the efficient use of energy and, therefore, enhance economic growth.
\end{abstract}

\section{Keywords}

Energy Consumption, Economic Growth, Granger Causality, Brazil

\section{Introduction}

Energy is the foundation of economic development and constitutes one of the vital infrastructure investments in social development. Both economy and energy consumption in Brazil have been growing rapidly. In the recent five years (2003-2008), Brazil has experienced greater growth rates in both energy use (4.18\%) and income

${ }^{*}$ Corresponding author.

How to cite this paper: Pao, H.-T., Li, Y.-Y. and Fu, H.-C. (2014) Causality Relationship between Energy Consumption and Economic Growth in Brazil. Smart Grid and Renewable Energy, 5, 198-205. http://dx.doi.org/10.4236/sgre.2014.58019 
(4.81\%) than the global growth rates for corresponding variables. The world's recent five-year growth rates in energy use and real GDP are $2.97 \%$ and $3.43 \%$, respectively. The Olympic Committee has chosen Brazil as the host country for the 2016 Olympic Games, highlighting the fact that Brazil is one of the future bright stars of the world. Official energy projections for Brazil indicate a continuing increase in demand for energy, in the next two decades.

There are numerous studies that deal with the causality relationship between energy consumption and economic growth. The findings from the studies vary not only across countries but also across methodologies for the same country. In a summary of the literature on the causal relationship between energy consumption and economic growth, there is evidence to support bidirectional or unidirectional causality, or no causality, between energy consumption and economic growth.

Evidence in either direction will have a significant bearing on policy. If, for example, there is unidirectional causality running from economic growth to energy consumption, it could imply that energy conservation policies may be implemented with little or no adverse effect on economic growth. Unidirectional causality running from economic growth to energy consumption was revealed by Ghosh [1] for India, by Mozumder and Marathe [2] for Bangladesh, by Narayan and Smyth [3] for Australia, by Yoo [4] for Indonesia and Thailand, and by Chen et al. [5] for Korea, Singapore, India, Malaysia and the Philippines.

In contrast, if a unidirectional causality runs from energy consumption to economic growth, reducing energy consumption could lead to a fall in economic growth while increasing it may contribute towards a country's economic growth. Unidirectional causality running from energy consumption to economic growth was revealed by Shiu and Lam [6] and Yuan et al. [7] for China, by Wolde-Rufael [8] for Shanghai, China, by Ho and Siu [9] for Hong Kung, by Pao et al. [10] for MIST countries, by Lee and Chang [11] for Taiwan, and by Chen et al. [5] for Indonesia.

On the other hand, if bidirectional causality is found, economic growth may demand more energy whereas more energy consumption may induce economic growth. Energy consumption and economic growth may complement each other and energy conservation measures may negatively affect economic growth. For example, Jumbe [12] for Malawi, Tang [13] and Yoo [4] for Malaysia, Yoo [4] for Singapore, Morimoto and Hope [14] for Sri Lanka, and Pao and Fu [15] [16] for Brazil found bidirectional causality between energy consumption and economic growth. In addition, Chen et al. [5] found bidirectional causality for 10 Asian countries using panel data.

Finally, no causality in either direction would indicate that energy conservation policies may not affect economic growth, and rise in real income may not affect electricity consumption. Chen et al. [5] found that there was no causality between economic growth and energy consumption in China, Taiwan and Thailand.

The purpose of this study is to investigate the causality relationship between energy consumption and economic growth, and to obtain policy implications from the results in Brazil. This purpose is accomplished by the following steps: First, stationarity and co-integration are tested; second, error-correction models are estimated to test for the Granger causality; finally, the F-tests are performed to determine the joint significance levels of causality between the two variables.

The remainder of this paper is organized as follows: Section 2 outlines the model and methodology. Section 3 discusses the data and empirical findings. The final section summarizes and concludes the paper.

For modeling purposes, all of the data were converted into natural logarithms prior to conducting the empirical analysis. Thus, the series can be interpreted in growth terms after taking the first difference into account.

\section{Model and Methodology}

\subsection{Model}

Following the empirical literature in energy economics, it is plausible to form a long-run relationship between energy consumption and economic growth in linear logarithm form, as follows:

$$
\mathrm{LEC}_{t}=\beta_{0}+\beta_{1} \mathrm{LGDP}_{t}+u_{t}
$$

where LEC and LGDP represent natural logarithms of energy consumption and real GDP, respectively. The error term, $u_{t}$, is assumed to be independent and identically distributed with a zero mean and a constant variance. The long-run income elasticity is given by: 


$$
\frac{\partial \mathrm{LEC}}{\partial \mathrm{LGDP}}=\beta_{1}
$$

The signs of $\beta_{1}$ is expected to be positive because a higher level of economic growth should stimulate energy use.

\subsection{Econometric Methodology}

The empirical analysis tests for the existence of a long-term relationship between the variables in Equation (1) while using the vector error-correction model to capture the Granger causality between variables. A three-step procedure is performed. First, we check the integration order of each variable, since various co-integration tests are only valid if the variables have the same order of integration. The three unit root tests Augmented Dickey-Fuller (ADF) [17], the Phillips-Perron (PP) [18] and Kwiatkowski-Phillips-Schmidt-Shin (KPSS) [19] are used to investigate the stationarity and the integration order of the variables. In terms of literature, tests designed on the basis of the null hypothesis that a series is I(1) have a low power of rejecting the null. Hence, KPSS is sometimes used to complement the widely used ADF and PP tests in order to obtain robust results.

Second, when all of the series of the same order are integrated, the Johansen maximum likelihood method [20] is used to test the co-integration relationship between the variables in Equation (1). If co-integration exists among the variables, OLS applied to estimate Equation (1) does not lead to a spurious regression result. Furthermore, the parameters estimated by OLS are super-consistent [21]. The existence of co-integration indicates that there are long-run equilibrium relationships between the variables, and thereby, Granger causality exists between them in at least one direction [22] [23].

Finally, if all of the variables are I(1) and co-integrated, the error correction model (ECM) is used for correcting any disequilibrium in the co-integration relationship, captured by the error-correction term (ECT), as well as testing for long-run and short-run causality among the co-integrated variables. The ECM for Equation (1) is specified as follows:

$$
\begin{aligned}
& \Delta \mathrm{LEC}_{t}=\gamma_{10}+\sum_{i=1}^{n_{1}} \gamma_{11 i} \Delta \mathrm{LEC}_{t-i}+\sum_{i=1}^{k_{1}} \gamma_{12 i} \Delta \mathrm{LGDP}_{t-i}+\delta_{1} \mathrm{ECT}_{t-1}+\mu_{1 t} \\
& \Delta \mathrm{LGDP}_{t}=\gamma_{20}+\sum_{i=1}^{n_{2}} \gamma_{21 i} \Delta \mathrm{LGDP}_{t-i}+\sum_{i=1}^{k_{2}} \gamma_{22 i} \Delta \mathrm{LEC}_{t-i}+\delta_{2} \mathrm{ECT}_{t-1}+\mu_{2 t}
\end{aligned}
$$

where

$$
\mathrm{ECT}_{t-1}=\mathrm{LEC}_{t-1}-b_{0}-b_{1} \mathrm{LGDP}_{t-1}
$$

is derived from the long-term co-integration relationship described in Equation (1). The sign $\Delta$ is the first-difference operator; the optimum lag lengths $n_{i}$ and $k_{i}$ are determined on the basis of Akaike's information criteria (AIC); and $\mu_{i t}$ are the serially uncorrelated error terms. The parameter $\delta_{1}$ is interpreted as being the speed of the adjustment coefficient which measures the speed at which the values of LEC come back to long-term equilibrium levels, once LEC violates the long-run equilibrium relationship. The negative sign of the estimated speed of adjustment coefficient is in accord with the convergence toward long run equilibrium [24].

The ECM represented by Equation (3) includes both the dependent variables with their own lags and the previous disequilibrium in terms of ECT $_{t-1}$. This specification can test the short-run and long-run causality among co-integrated variables. In terms of short-run causality in Equation (3), the causality runs from the real output to energy consumption if the joint null hypothesis, $\gamma_{12 i}=0, \forall i$ is rejected via a Wald test, whereas the causality runs from energy consumption to the real output if the joint null hypothesis $\gamma_{21 i}=0, \forall i$ is rejected. With respect to long-run causality if the null hypothesis $\delta_{1}=0$ is rejected, energy consumption respond to deviations from the long-run disequilibrium. If the null hypothesis $\delta_{2}=0$ is rejected, then the real output responds to deviations from the long-run equilibrium. Finally, the strong Granger-causality runs from the real output to energy consumption if the null hypothesis $\gamma_{12 i}=\delta_{1}=0, \forall i$ is rejected, whereas the strong Granger-causality runs from energy consumption to real output if the null hypothesis $\gamma_{21 i}=\delta_{2}=0, \forall i$ is rejected.

\section{Empirical Findings}

This study collects annual data on energy consumption and real GDP for the period between 1980 and 2008 
from the Energy Information Administration (EIA) and the World Development Indicators (WDI). Real GDP is measured in US dollars at 2000 prices. Energy consumption is measured in BTU (British thermal unit). Table 1 displays the summary statistics associated with the two variables.

Figure 1 shows the change trend of each series for Brazil, all of which have increased across time. The energy consumption than the real GDP has exhibited a larger coefficient of variation (CV) shown in Table 1. Table 2 shows average percentage growth rates in the years to 2008 of each series. Fifteen-year, ten-year, and fiveyear growth rates are calculated as the growth between 1993 and 2008, 1998 and 2008, and 2003 and 2008, respectively. In the most recent five years (2003-2008), Brazil has experienced a greater growth rates in both energy use (4.18\%) and income (4.81\%) than the global growth rates for corresponding variables. The world's most recent five-year growth rates in energy use and real GDP are $2.97 \%$ and $3.43 \%$, respectively.

For the time period between 1980 and 2008, the energy consumption-income relationship (Figure 2) shows a monotonic increase in Brazil. Therefore, Equation (1) is employed to examine how the energy consumption and economic growth are related in the long-run. Both the values of adjusted $\mathrm{R}^{2}$ and Jarque and Bera (JB) statistic [25] shown in Table 3 indicate Equation (1) is appropriate to test whether the two series are co-integrated. Table 4 shows the stationarity results for both LEC and LGDP through three different unit root tests, namely ADF, PP, and KPSS. All of the series appear to contain a unit root in their levels but are stationary in their first differ-

Energy Consumption(Billion Btu)

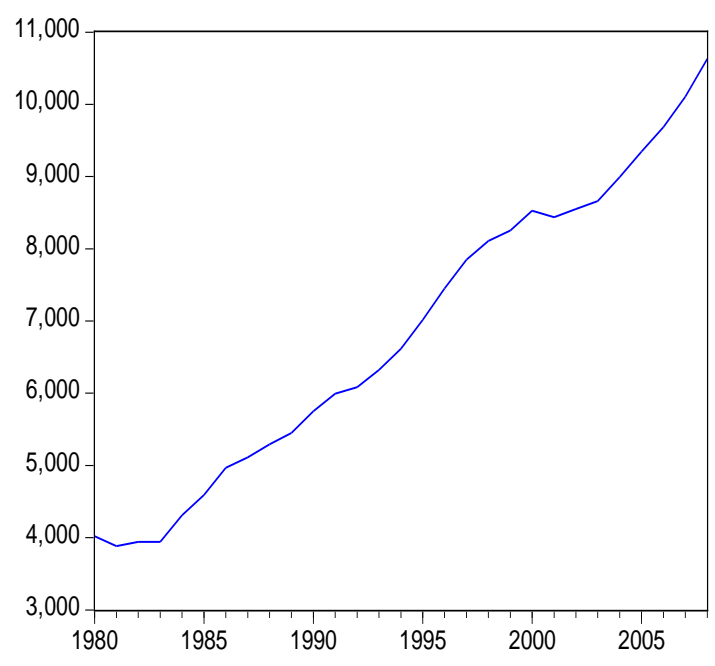

(a)

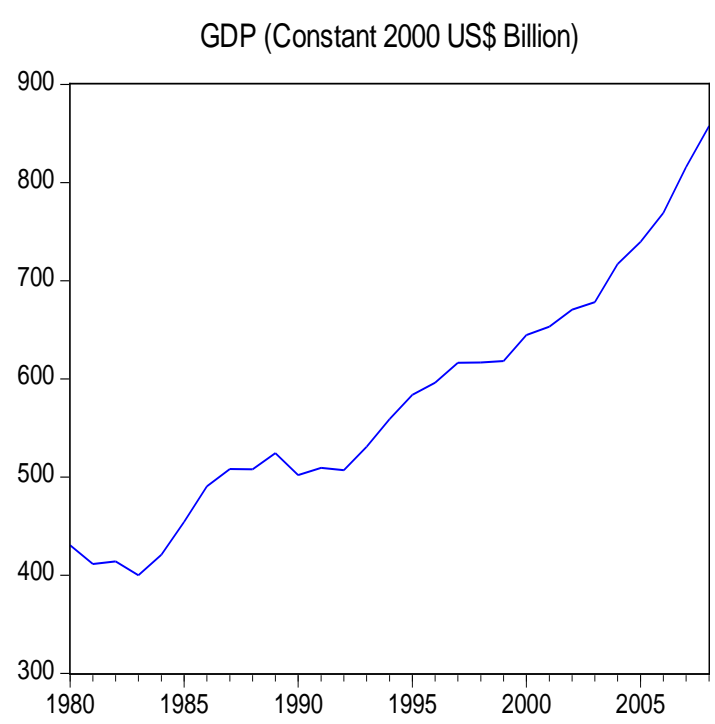

(b)

Figure 1. Time series plots of the energy consumption and real GDP, 1980-2008.

Table 1. Summary statistics for Brazil, 1980-2008.

\begin{tabular}{cccccc}
\hline & $\begin{array}{c}\text { Energy consumption } \\
\text { (Billion Btu) }\end{array}$ & & \multicolumn{2}{c}{ Real GDP } \\
(constant 2000 US\$ Billions)
\end{tabular}

Table 2. Average growth rates in percentages to 2008 for each variable.

\begin{tabular}{ccccc} 
& \multicolumn{2}{c}{ Brazil } & & World \\
& Energy consumption & Real GDP & Energy consumption & Real GDP \\
\hline 15 year growth & 5.15 & 3.25 & 2.41 & 3.11 \\
10 year growth & 2.75 & 3.36 & 4.09 & 2.97 \\
5 year growth & 4.18 & 4.81 & 3.43 \\
\hline
\end{tabular}




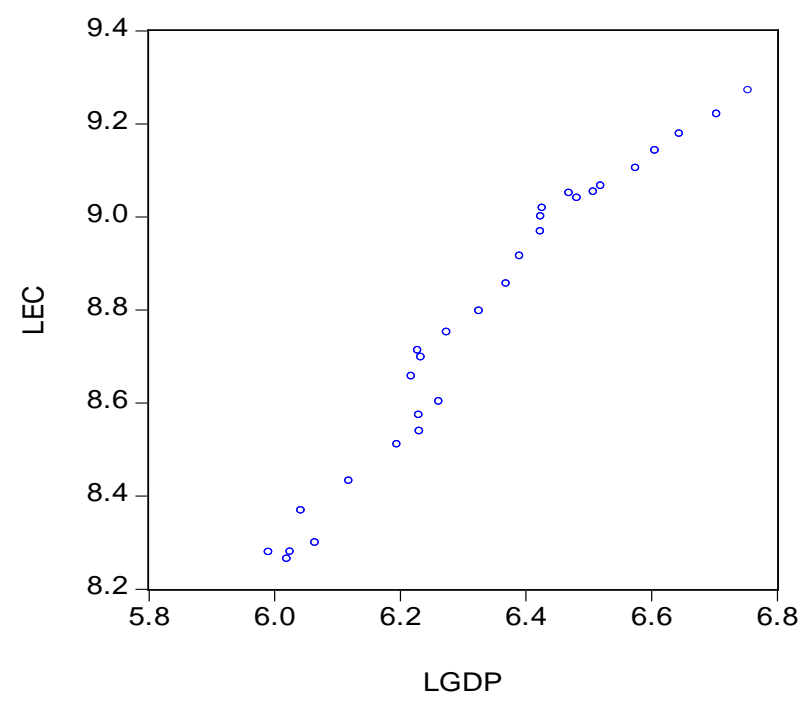

Figure 2. The $\ln ($ energy consumption)-ln(GDP) plots for Brazil, 1980-2008.

Table 3. Coefficients of Equations (1).

\begin{tabular}{ccccc}
\hline \multicolumn{3}{c}{ Indep. var. } & & \\
Dep. var. & LGDP & Intercept & Adj-R2 & JB \\
\hline & $1.454^{*}$ & -0.431 & 0.9570 & 1.909 \\
LEC & $(24.977)$ & $(-1.168)$ & 0.385 & \\
\hline
\end{tabular}

Note: Figures in parenthesis indicate t-statistics. ${ }^{*}$ indicates the rejection of a null hypothesis at $1 \%$ level of significance.

Table 4. Results of unit roots tests.

\begin{tabular}{cccccc} 
& & & & \\
& ADF & PP & KPSS \\
& Level & $1^{\text {st }}$ diff. & Level & $1^{\text {st }}$ diff. & Level \\
\hline LEC & -0.2761 & $-4.2798^{*}$ & -0.3208 & $-4.2760^{*}$ & $0.6629^{* *}$ diff. \\
LGDP & 2.2491 & $-4.2497^{*}$ & 0.5498 & $-4.2427^{*}$ & 0.0882 \\
\hline
\end{tabular}

Note: All unit roots (except the KPSS) have a null hypothesis in that the series has a unit root against the alternative of being stationary. The null of KPSS states that the variable is stationary. Individual intercepts are included in test regressions. ${ }^{*}$ and ${ }^{* *}$ mean that the null of the unit root test is rejected at a $1 \%$ and $5 \%$ level. The lag lengths are selected using AIC.

ence, indicating that they are integrated at order one i.e., $I(1)$.

The next step is to test whether LEC and LGDP are co-integrated and Table 5 shows the results of the Johansen test. The trace and eigenvalue tests reject the hypothesis of no co-integrating equation at a $5 \%$ level of significance, and have at least one co-integration equation existence. The estimated co-integrating vector normalized with respect to LEC is $(1,1.454)$ shown in Table 3 . This implies that a $1 \%$ increase in the growth of income will lead to an increase of growth in energy consumption by $1.454 \%$ in the long run. Thus, in the long-run equilibrium, energy consumption appears to be real GDP elastic in Brazil.

Co-integration implies the existence of causality, at least in one direction. However, it does not indicate the direction of the causal relationship. Hence, to shed light on the direction of causality, ECM based causality tests are performed. The short-run $\chi^{2}$-statistics, long-run $t$-statistics and joint $F$-statistics for Equation (3) are reported in Table 6. The short-run dynamics suggests unidirectional causality from energy consumption to real output. With respective to the long-run dynamics, the estimated coefficient of the ECT term is statistically significant with a negative sign in each equation, i.e. a change in one variable is expected to affect the other variables through a feedback system. This implies that there is a long term bi-directional causal relationship between them. Moreover, the estimated coefficients of the interaction terms are statistically significant in Equations (3a) and 
(3b). This implies that a bidirectional strong Granger-causality is running between real output and energy consumption. In other words, whenever a shock occurs in the system, each variable makes a short-run adjustment to restore the long-run equilibrium. These findings are broadly consistent with the results of the BRICs as a whole [26] [27]. In Figure 3, we summarize all the causality results.

\section{Conclusion and Policy Implications}

This study has investigated the causality relationship between energy consumption and economic growth in Brazil during the period of 1980-2008. Granger causality test was used to examine the causal relationship between variables. Prior to testing for causality, the ADF, PP and KPSS unit root tests and Johansen co-integration rank test were used to examine the unit roots and the co-integration. The Johansen co-integration test indicates a long-run equilibrium relationship between energy consumption and economic growth, and energy consumption appears to be real GDP elastic. A $1 \%$ increase in the growth of income will lead to an increase of growth in energy consumption by $1.454 \%$ in the long run. This elasticity suggests that energy consumption has a great positive influence on changes in income.

A bidirectional strong Granger causality between economic growth and energy consumption implies that the two variables are jointly determined and affected at the same time. That is, an increase in energy consumption raises economic growth and vice versa. This can be explained by at least three factors: scale, technique effects, and energy efficiency. Firstly, the scale effect occurs as energy consumption increase with the size of the economy. Secondly, the energy-income relationship depends on the techniques of production. An improvement in the techniques of production, i.e., the technique effect, may reduce the amount of energy use and increase profitability per unit of production. Finally, in pursuit of continuing economic growth, Brazil's government will need to put more effort into improving the energy efficiency of energy appliances and equipment, reducing the loss in power transmission and distribution, and introducing various kinds of tariff reforms to control energy consumption patterns. Figures for 2007 show that Brazil consumed 10046 Btu of energy for every dollar of GDP output at market exchange rates, which is only marginally higher than the world energy intensity of $9800 \mathrm{Btu}$. So, Brazil was the most efficient energy user. The disconcerting note in Brazil's record of energy use is that, while

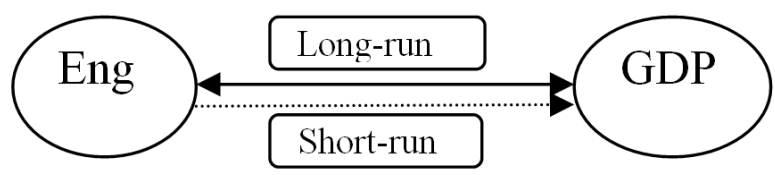

Figure 3. Causality results.

Table 5. Results of Johansen's co-integration test.

\begin{tabular}{cccccc}
\hline Eigenvalue & Trace Stat. & 5\% critical value & Max Eigen. Stat. & 5\% critical value & Number of co-integrations \\
\hline 0.673 & $36.765^{*}$ & 25.872 & $29.023^{*}$ & 19.387 & None \\
0.258 & 7.742 & 12.518 & 7.742 & 12.518 & At most 1 \\
\hline
\end{tabular}

Note: The optimal lag lengths are selected using AIC. ${ }^{*}$ indicates the rejection of a null hypothesis at $5 \%$ level of significance.

Table 6. Results of causality tests.

\begin{tabular}{|c|c|c|c|c|c|}
\hline \multicolumn{6}{|c|}{ Source of causation (independent variables) } \\
\hline & \multicolumn{2}{|c|}{ Short-run } & Long-run & \multicolumn{2}{|c|}{ Joint (short-run/long-run) } \\
\hline & \multicolumn{2}{|c|}{$\chi^{2}$-statistics } & $t$-statistics & \multicolumn{2}{|c|}{ F-statistics } \\
\hline & $\triangle \mathrm{LEC}$ & $\triangle \mathrm{LGDP}$ & ECT & $\Delta \mathrm{LEC} / \mathrm{ECT}$ & $\Delta \mathrm{GDP} / \mathrm{ECT}$ \\
\hline$\Delta \mathrm{LEC}$ & & 1.116 & $-0.199^{*}$ & & $5.640^{* *}$ \\
\hline$\Delta \mathrm{LGDP}$ & $9.527^{*}$ & & $-0.358^{*}$ & $11.962^{*}$ & \\
\hline
\end{tabular}

Note: The optimal lag lengths are selected using AIC. ${ }^{*}$ and ${ }^{* *}$ indicate a $1 \%$ and $5 \%$ level of significance, respectively. 
energy intensity has decreased by an annual average rate of $0.27 \%$ in the South and Central American region as a whole, Brazil has shown an annual average increase of $0.26 \%$ in energy intensity since the nineties. But it is still credible that the energy intensity in Brazil is almost a third lower than that of Venezuela, the largest source of oil in South America. However, Brazil is the $10^{\text {th }}$ largest energy consumer in the world and the third largest in the Western Hemisphere, behind the United States and Canada. Thus, an improvement in energy efficiency is essential. Thus, Brazil should adopt a dual strategy of increasing investment in energy infrastructure, and stepping up energy conservation policies to reduce any unnecessary waste of energy, in order to reduce emissions and avoid having a negative effect on economic growth by reducing energy consumption. In contrast, energy conservation is expected to increase the efficient use of energy and, therefore, enhance economic growth.

\section{References}

[1] Ghosh, S. (2002) Electricity Consumption and Economic Growth in India. Energy Policy, 30, 125-129. http://dx.doi.org/10.1016/S0301-4215(01)00078-7

[2] Marathe, A. and Mozumder, P. (2007) Causality Relationship between Electricity Consumption and GDP in Bangladesh. Energy Policy, 35, 395-402. http://dx.doi.org/10.1016/j.enpol.2005.11.033

[3] Narayan, P.K. and Smyth, R. (2005) Electricity Consumption, Employment and Real Income in Australia Evidence from Multivariate Granger Causality Tests. Energy Policy, 33, 1109-1116. http://dx.doi.org/10.1016/j.enpol.2003.11.010

[4] Yoo, S.H. (2006) The Causal Relationship between Electricity Consumption and Economic Growth in the ASEAN countries. Energy Policy, 34, 3573-3582. http://dx.doi.org/10.1016/j.enpol.2005.07.011

[5] Chen, S.T., Kuo, H.I. and Chen, C.H. (2007) The Relationship between GDP and Electricity Consumption in 10 Asian countries. Energy Policy, 35, 2611-2621. http://dx.doi.org/10.1016/j.enpol.2006.10.001

[6] Shiu, A. and Lam, P.L. (2004) Electricity Consumption and Economic Growth in China. Energy Policy, 32, 47-54. http://dx.doi.org/10.1016/S0301-4215(02)00250-1

[7] Yuan, J., Zhao, C., Yu, S. and Hu, Z. (2007) Electricity Consumption and Economic Growth in China: Cointegration and co-feature analysis. Energy Economics, 29, 1179-1191. http://dx.doi.org/10.1016/j.eneco.2006.09.005

[8] Wolde-Rufael, Y. (2004) Disaggregated Industrial Energy Consumption and GDP: The Case of Shanghai. Energy Economics, 26, 69-75. http://dx.doi.org/10.1016/S0140-9883(03)00032-X

[9] Ho, C.Y. and Siu, K.W. (2007) A Dynamic Equilibrium of Electricity Consumption and GDP in Hong Kong: An Empirical Investigation. Energy Policy, 35, 2507-2013. http://dx.doi.org/10.1016/j.enpol.2006.09.018

[10] Pao, H.T., Li, Y.Y. and Fu, H.C. (2014) Clean Energy, Non-Clean Energy, and Economic Growth in the MIST Countries. Energy Policy, 67, 932-942. http://dx.doi.org/10.1016/i.enpol.2013.12.039

[11] Lee, C.C. and Chang, C.P. (2005) Structural Breaks, Energy Consumption, and Economic Growth Revised: Evidence from Taiwan. Energy Economics, 27, 857-872. http://dx.doi.org/10.1016/j.eneco.2005.08.003

[12] Jumbe, C.B.L. (2004) Cointegration and Causality between Electricity Consumption and GDP: Empirical Evidence from Malawi. Energy Economics, 26, 61-68. http://dx.doi.org/10.1016/S0140-9883(03)00058-6

[13] Tang, C.F. (2008) A Re-Examination of the Relationship between Electricity Consumption and Economic Growth in Malaysia. Energy Policy, 36, 3077-3085. http://dx.doi.org/10.1016/j.enpol.2008.04.026

[14] Morimoto, R. and Hope, C. (2004) The Impact of Electricity Supply on Economic Growth in Sri Lanka. Energy Economics, 26, 77-85. http://dx.doi.org/10.1016/S0140-9883(03)00034-3

[15] Pao, H.T. and Fu, H.C. (2013) Renewable Energy, Non-Renewable Energy and Economic Growth in Brazil. Renewable and Sustainable Energy Reviews, 25, 381-392. http://dx.doi.org/10.1016/j.rser.2013.05.004

[16] Pao, H.T. and Fu, H.C. (2013) The Causal Relationship between Energy Resources and Economic Growth in Brazil. Energy Policy, 61, 793-801. http://dx.doi.org/10.1016/j.enpol.2013.06.113

[17] Dickey, D.A. and Fuller, W.A. (1981) Likelihood Ratio Statistics for Autoregressive Time Series with a Unit Root. Econometrica, 49, 1057-1072. http://dx.doi.org/10.2307/1912517

[18] Phillips, P.C. and Perron, P. (1988) Testing for a Unit Root in Time Series Regression. Biometrika, 75, 335-346. http://dx.doi.org/10.1093/biomet/75.2.335

[19] Kwiatkowski, D., Phillips, P., Schmidt, P. and Shin, Y. (1992) Testing the Null Hypothesis of Stationarity against the Alternative of a Unit Root: How Sure Are We that Economic Time Series Have a Unit Root? Journal of Econometrics, 54, 159-178. http://dx.doi.org/10.1016/0304-4076(92)90104-Y

[20] Johansen, S. and Juselius, K. (1990) Maximum Likelihood Estimation and Inferences on Cointegration-With Appli- 
cations to the Demand for Money. Oxford Bulletin of Economics and Statistics, 52, 169-209. http://dx.doi.org/10.1111/j.1468-0084.1990.mp52002003.x

[21] Alves, D.C.O. and Bueno, R.D. (2003) Short-Run, Long-Run and Cross Elasticities of Gasoline Demand in Brazil. Energy Economics, 25, 191-199. http://dx.doi.org/10.1016/S0140-9883(02)00108-1

[22] Engle, R.F. and Granger, C.W.J. (1987) Co-Integration and Error Correction: Representation, Estimation, and Testing. Econometrica, 55, 251-276. http://dx.doi.org/10.2307/1913236

[23] Oxley, L. and Greasley, D. (2008) Vector Autoregression, Cointegration and Causality: Testing for Causes of the British Industrial Revolution. Applied Economics, 30, 1387-1397. http://dx.doi.org/10.1080/000368498325002

[24] Pao, H.T. and Tsai, C.M. (2011) Modeling and Forecasting the $\mathrm{CO}_{2}$ Emissions, Energy Consumption, and Economic Growth in Brazil. Energy, 36, 2450-2458. http://dx.doi.org/10.1016/j.energy.2011.01.032

[25] Jarque, C.M. and Bera, A.K. (1980) Efficient Tests for Normality, Homoscedasticity and Serial Independence of Regression Residuals. Economics Letters, 6, 255-259. http://dx.doi.org/10.1016/0165-1765(80)90024-5

[26] Pao, H.T. and Tsai, C.M. (2010) $\mathrm{CO}_{2}$ Emissions, Energy Consumption and Economic Growth in BRIC Countries. Energy Policy, 38, 7850-7860. http://dx.doi.org/10.1016/j.enpol.2010.08.045

[27] Pao, H.T. and Tsai, C.M. (2011) Multivariate Granger Causality between $\mathrm{CO}_{2}$ Emissions, Energy Consumption, FDI (Foreign Direct Investment) and GDP (Gross Domestic Product): Evidence from a Panel of BRIC (Brazil, Russian Federation, India, and China) Countries. Energy, 36, 685-693. http://dx.doi.org/10.1016/j.energy.2010.09.041 
Scientific Research Publishing (SCIRP) is one of the largest Open Access journal publishers. It is currently publishing more than 200 open access, online, peer-reviewed journals covering a wide range of academic disciplines. SCIRP serves the worldwide academic communities and contributes to the progress and application of science with its publication.

Other selected journals from SCIRP are listed as below. Submit your manuscript to us via either submit@scirp.org or Online Submission Portal.
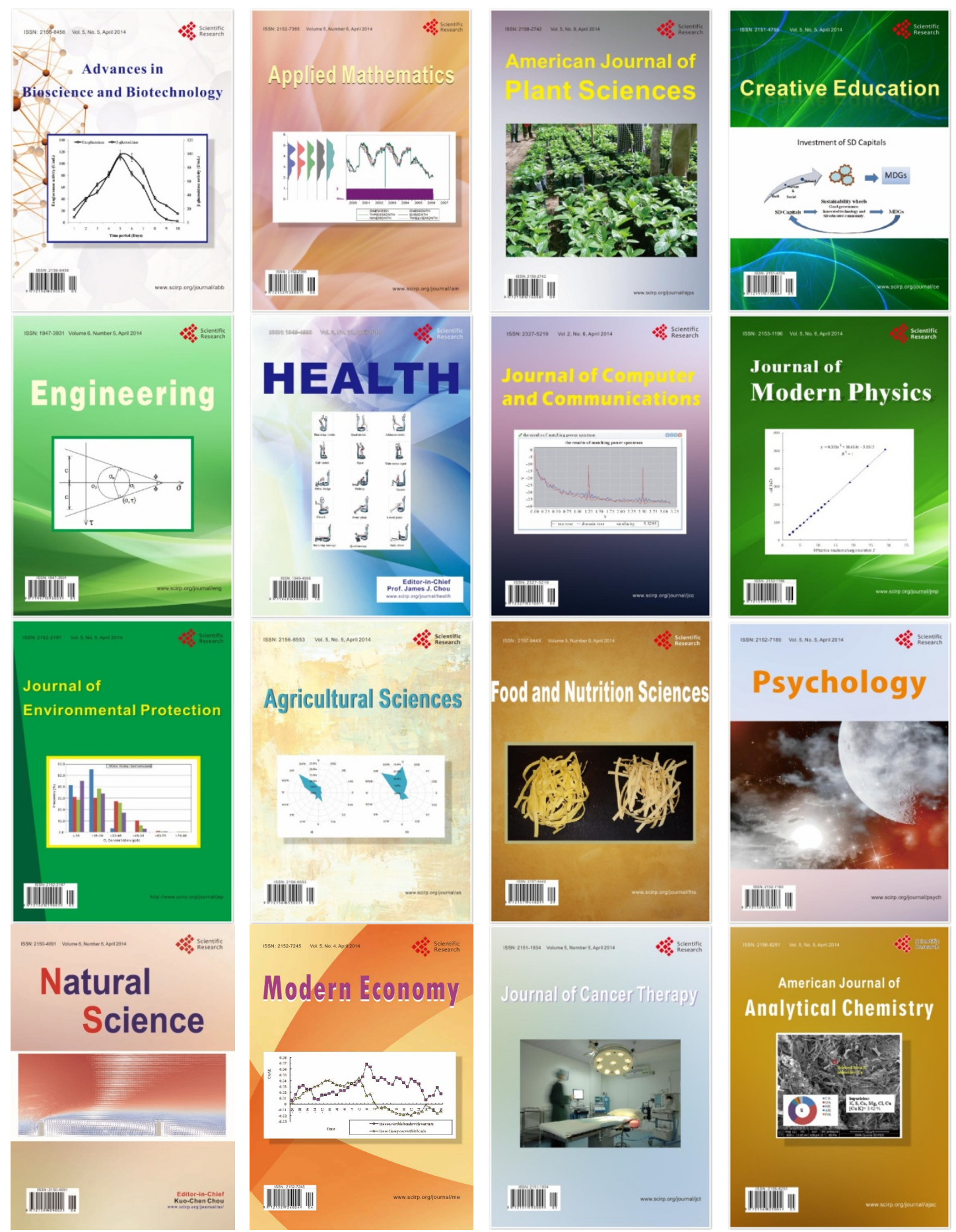